\title{
Genome-wide microarray gene expression, array-CGH analysis, and telomerase activity in advanced ovarian endometriosis: A high degree of differentiation rather than malignant potential
}

\author{
MENELAOS ZAFRAKAS ${ }^{1,2}$, BASIL C. TARLATZIS ${ }^{2}$, THOMAS STREICHERT ${ }^{3}$, FOTIOS POURNAROPOULOS ${ }^{2}$, \\ UTE WÖLFLE $^{4}$, SERGE J. SMEETS ${ }^{5}$, BRITTA WITTEK ${ }^{1}$, GRIGORIOS GRIMBIZIS ${ }^{2}$, \\ RUUD H. BRAKENHOFF ${ }^{5}$, KLAUS PANTEL ${ }^{4}$, JOHN BONTIS ${ }^{2}$ and CAGATAY GÜNES ${ }^{1}$ \\ ${ }^{1}$ Heinrich-Pette-Institute for Experimental Virology and Immunology, University of Hamburg, \\ Martinistr. 52, 20251 Hamburg, Germany; ${ }^{2}$ First Department of Obstetrics and Gynecology, Aristotle University \\ of Thessaloniki, Papageorgiou General Hospital, Periferiaki Odos Thessalonikis, N. Efkarpia, 56403 Thessaloniki, Greece; \\ Institutes for ${ }^{3}$ Clinical Chemistry, ${ }^{4}$ Tumor Biology, University Hospital Hamburg-Eppendorf, Martinistr. 52 , \\ 20246 Hamburg, Germany; ${ }^{5}$ Section Tumor Biology, Department of Otolaryngology/Head and Neck Surgery, \\ VU University Medical Center, De Boelelaan 1117, 1081HV Amsterdam, The Netherlands
}

Received October 3, 2007; Accepted December 3, 2007

\begin{abstract}
The aim of the present study was to investigate whether endometriosis and cancer share common molecular characteristics. Tissue samples were collected prospectively during diagnostic laparoscopy of patients with primary infertility. Using high-density oligonucleotide microarrays, (Affymetrix Gene Chip HG-U133 Set) the genome-wide gene expression profile of advanced ovarian endometriosis was analyzed compared with matched normal endometrium. Expression of TERT, the gene encoding the telomerase reverse transcriptase subunit, and telomerase activity were analyzed in eutopic and ectopic endometrium. Genome-wide, highresolution array-CGH was used to screen for genomic aberrations in endometriosis. Expression microarray data were validated quantitatively with RT-PCR. The genes RARRES1 and RARRES2 (retinoic acid receptor responder 1 and 2) were found to be up-regulated in endometriosis, suggesting a high degree of differentiation. Consistently, down-regulated genes included those involved in the cell cycle, cell metabolism and homeostasis. Expression of TERT and telomerase activity were present in eutopic but absent in ectopic endometrium. Array$\mathrm{CGH}$ revealed a normal genomic pattern without gross amplifications and deletions. In conclusion, these data suggest
\end{abstract}

Correspondence to: Dr Cagatay Günes, Heinrich-Pette-Institute for Experimental Virology and Immunology, University of Hamburg, Martinistr. 52, 20251 Hamburg, Germany

E-mail: cagatay.guenes@hpi.uni-hamburg.de

Key words: endometriosis, endometrium, microarrays, array-CGH, telomerase that advanced ovarian endometriosis represents a highly differentiated tissue with minimal or no malignant potential.

\section{Introduction}

Endometriosis is the presence of endometrial tissue, including endometrial glandular and stromal cells, outside the uterine cavity. It is usually confined to the pelvis, where it may be associated with pelvic pain and infertility, and in rare cases it can be found in distant sites, such as the thorax and skin $(1,2)$. It is estimated that endometriosis affects $5-15 \%$ of 'normal' and up to $60-80 \%$ of women with pelvic pain and/or infertility (3).

The most widely accepted theory on the etiopathogenesis of endometriosis is the theory of ectopic transplantation of endometrium, mainly through reflux menstruation (4). Similarly, endometriosis in distant sites can be explained by migration of endometrial cells through lymphatic and blood vessels (5). In this way, endometriosis represents a paradigm of benign dissemination and metastasis. At the cellular level it is characterized by monoclonal growth and can reveal features of malignant behaviour including local invasion and metastasis (6). Therefore, endometriosis might serve as a model to study the molecular and genomic requirements needed for dissemination of non-malignant cells.

The association of endometriosis with cancer is unclear. Although it is not neoplastic and does not create a cachectic or catabolic state, certain processes characterizing metastasis and carcinogenesis are also seen in endometriosis. These include cell motility, adhesion, homing and invasion, immunologic factors, maintenance of the original structure and tissue architecture at the ectopic site, angiogenesis and metaplasia (6). Moreover, evidence exists that endometriotic lesions present genetic changes similar to certain malignancies $(7,8)$. Furthermore, a direct association of ovarian cancer and endometriosis has been previously described in numerous 
case reports and case series (9-12). Like any other tissue, endometriotic lesions may well undergo malignant transformation. On the other hand, large retrospective, epidemiologic studies show that women with endometriosis have an increased risk of ovarian and other types of cancer compared with the normal population $(13,14)$.

Given the multitude of cellular and molecular mechanisms involved in endometriosis formation and maintenance and the gap of knowledge concerning the association of endometriosis with tumorigenesis and metastasis, we conducted a large-scale gene expression analysis of ovarian endometriotic lesions and corresponding eutopic endometrium. To examine for genomic variations which might influence the gene expression profile, we performed an array-CGH analysis on selected endometriotic tissue samples, including samples analyzed with gene expression microarrays.

\section{Materials and methods}

Tissue samples. Tissue samples were collected prospectively from patients with primary infertility, who underwent laparoscopy during the proliferative phase of the menstrual cycle, between day 4 and 10 after the last menstrual period. All patients tested negative on a urine pregnancy test, had an otherwise healthy medical history, and were not under any hormone treatment. A total of 14 endometriotic ovarian cysts were excised, with operative time ranging between 30 and $45 \mathrm{~min}$ in all cases. All patients had moderate to severe endometriosis - stages III and IV according to the Revised American Fertility Society Classification for Endometriosis. Biopsies of normal endometrium were possible in four of these cases. Diagnosis was confirmed with histopathological examination in all cases. Biopsy material was stored in liquid nitrogen immediately after surgery (10-30 min after excision). An independent academic board approved the protocol prior to the study, and all specimens were obtained in accordance with the Declaration of Helsinki of 1975 on Human Experimentation. For microarray studies, only endometriotic lesions with matched eutopic endometrium available were used (i.e. four cases). For array-CGH analysis, 10 endometriosis samples were used including the 4 cases from the gene expression analysis.

RNA preparation. Tissue specimens were homogenized in liquid nitrogen using pestle and mortar. Total RNA was prepared by lysing specimens in Trizol reagent according to the manufacturer's instructions (Invitrogen GmbH, Karlsruhe, Germany). Total RNA was cleaned-up using RNeasy Mini Kit according to the manufacturer's instructions (Qiagen GmbH, Hilden, Germany).

DNA preparation. All cryopreserved tissue samples were homogenized, and genomic DNA was isolated using the QiaDNA Isolation Kit (Qiagen $\mathrm{GmbH}$ ) according to the manufacturer's instructions.

Gene expression profiling. For all experiments, high-density oligonucleotide microarrays, screening for $>40,000$ human genes and expressed sequence tags ESTs (44,928 probe sets) were used (GeneChip HG-U133 Set; Affymetrix, Santa Clara,
CA). The targets for DNA-microarray analysis were prepared as described by the manufacturer. In brief, after RNA extraction, reverse transcription, cDNA clean-up, in vitro transcription and cRNA-labelling with biotin and fragmentation, cRNA was hybridized on the microarrays. The amount of total RNA used for cDNA-synthesis was $10 \mu \mathrm{g}$ for each reaction. GeneChip microarrays were hybridized with the targets for $16 \mathrm{~h}$ at $45^{\circ} \mathrm{C}$, and then washed and stained using the Affymetrix Fluidics Station according to the GeneChip Expression Analysis Technical Manual. Microarrays were scanned with a Hewlett-Packard-Agilent GeneChip scanner, and the signals were processed using the GeneChip expression analysis algorithm ver. 2 (Affymetrix). To compare samples and experiments, the trimmed mean signal of each array was scaled to a target intensity of 200 for A-Arrays and 80 for BArrays. Absolute and comparison analyses were performed with Affymetrix MAS 5.0 and DMT software using default parameters. In order to identify genes positively or negatively regulated, genes that were increased or decreased at least 2-fold compared to the baseline (eutopic endometrium) were selected (15). Annotations were further analyzed with interactive query analysis at www.affymetrix.com. Pathways and other functional groupings of genes were evaluated for differential regulation using the visualization tool GenMAPP (UCSF) as described previously $(16,17)$.

Radioactive $R T-P C R$. First-strand cDNA synthesis was performed using $1 \mu \mathrm{g}$ total RNA with the ThermoScript Reverse Transcriptase Kit (Invitrogen, Carlsbad, CA, USA) in the presence of $100 \mathrm{ng}$ oligo- $\mathrm{dT}_{20}$ in a volume of $20 \mu \mathrm{l}$ under the following conditions: $1 \mathrm{~h}$ at $50^{\circ} \mathrm{C}$ followed by $15 \mathrm{~min}$ at $75^{\circ} \mathrm{C}$, followed by $20 \mathrm{~min}$ at $37^{\circ} \mathrm{C}$ in the presence of 2 units of RNase $\mathrm{H}$ to digest the RNA. cDNA $(2 \mu \mathrm{l})$ was used for the PCR analysis in a total volume of $50 \mu 1$ containing $0.2 \mu \mathrm{M}$ specific primers, $10 \%$ DMSO, $1.5 \mathrm{mM} \mathrm{MgCl}_{2}, 0.2 \mathrm{mM}$ dNTPs and 1 unit of Taq polymerase (Eppendorf, Hamburg, Germany). The sequences of primers used were: RARRES1, 5'-GAG CGC TAC AAC CCA GAG TC-3' (forward) and 5'-GAA AGC CAA ATC CCA GAT GA-3' (reverse); RARRES2, 5'-GAC TGG AAG AAA CCC GAG TG-3' (forward) and 5'-CTT GGA GAA GGC GAA CTG TC-3' (reverse); LTBP2, 5'-CTG AAT CCG CCC AGT GAT AG-3', (forward) and 5'-ACA TTG GAA ATC TGG CTG CT-3' (reverse); TYMS , 5'-TTC AGG ACA GGG AGT TGA CC-3' (forward) and 5'-CAT GTC TCC CGA TCT CTG GT-3' (reverse); HMGCR, 5'-TCT CCG CAG GCT ATT TGT TC3' (forward) and 5'-TAA GGT CCC AGT CTT GCT TG-3' (reverse); hTERT, 5'-TCT GGA TTT GCA GGT GAA CAG CC-3' (forward) and 5'-GGG TGG CCA TCA GTC CAG GAT GG-3' (reverse); 36B4, 5'-GTG GGA GCA GAC AAT GTG GGC TCC-3' (forward) and 5'-ATG GAT CAG CCA AGA AGG CCT TGA C-3' (reverse); 18Sr RNA, 5'-GTT GCA AAG CTG AAA CTT AAA GG-3' (forward) and 5'-CCG ATC CGA GGG CCT CAC TAA ACC-3' (reverse). For radioactive PCR analysis, $2.5 \mu \mathrm{Ci}$ of $\left[\alpha^{-32} \mathrm{P}\right] \mathrm{dCTP}(3000 \mathrm{Ci} /$ mmol, Amersham Pharmacia Biotech, Freiburg, Germany) was added to the reaction. Amplification products were analyzed on $4 \%(36 B 4,18 S r R N A$ and $h T E R T)$ or $6 \%$ (RARRES1, RARRES2, LTBP2, TYMS and HMGCR) nondenaturing polyacrylamide gels, respectively. 
Table I. Up-regulated genes and ESTs in all 16 comparisons.

\begin{tabular}{llll}
\hline Fold-up & GenBank ID & \multicolumn{1}{c}{ Gene description } & Gene symbol \\
\hline 45.10 & NM_022844.1 & Myosin, heavy polypeptide 11, smooth muscle & MYH11 \\
17.37 & S55735.1 & Hypothetical protein MGC27165 & MGC27165 \\
09.85 & AW009747 & Homo sapiens cDNA FLJ20767 fis, clone COL06986 & TAGLN \\
07.54 & NM_003186.2 & Transgelin & RARRES1 \\
07.24 & NM_002888.1 & Retinoic acid receptor responder (tazarotene induced) 1 & CPVL \\
06.01 & NM_031311.1 & Carboxypeptidase, vitellogenic-like & IGKC \\
05.98 & AW404894 & Immunoglobulin constant & RARRES1 \\
05.66 & AI669229 & Retinoic acid receptor responder (tazarotene induced) 1 & SYNPO2 \\
04.76 & AI634580 & Synaptopodin 2 & IGJ \\
04.57 & AV733266 & Ig J polypeptide, linker protein for immunoglobulin $\alpha$ and $\mu$ polypeptides & LTBP2 \\
03.72 & NM_000428.1 & Latent transforming growth factor ß binding protein 2 & DKFZp761G058 \\
02.42 & AV706522 & Hypothetical protein DKFZp761G058 & PPAP2B \\
02.41 & BG538564 & Homo sapiens PRO2743 mRNA, complete cds & \\
02.15 & AA628586 & Phosphatidic acid phosphatase type 2B & \\
\hline
\end{tabular}

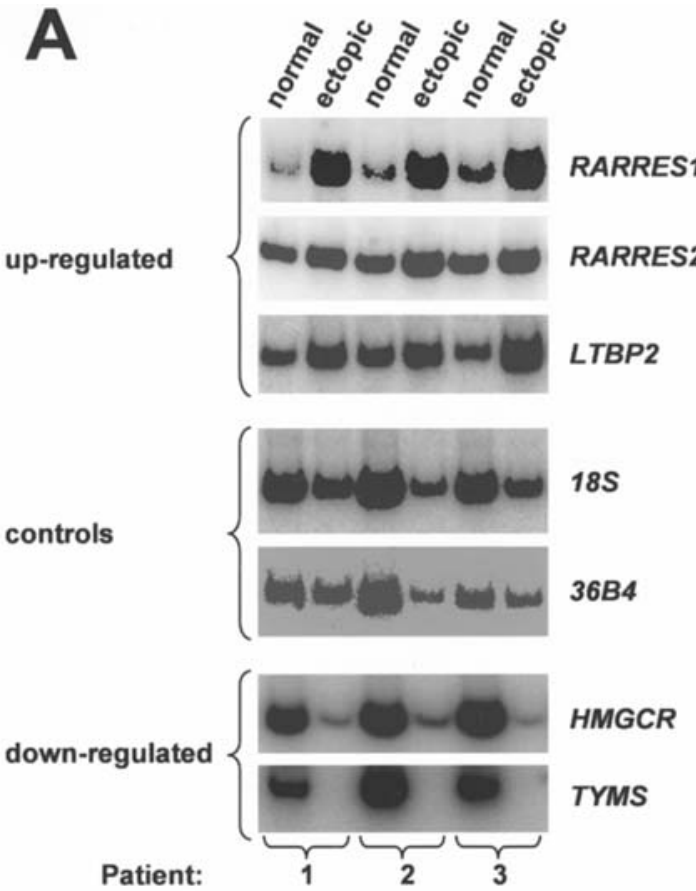

B

\begin{tabular}{|l|l|}
\hline & up-regulation \\
\hline RARRES1 & 15-fold \\
\hline RARRES2 & 9-fold \\
\hline LTBP2 & 7-fold \\
\hline
\end{tabular}

C

\begin{tabular}{|l|l|}
\hline & down-regulation \\
\hline HMGCR & 3,5 -fold \\
\hline TYMS & $\geq 3$-fold \\
\hline
\end{tabular}

Figure 1. RT-PCR analysis of selected genes confirming microarray data. (A) Total RNA was isolated from eutopic and ectopic endometrium of 3 patients and reverse transcribed. Amplification of the cDNAs was performed in the presence of trace amounts of $\left[\alpha^{-32} \mathrm{P}\right] \mathrm{dCTP}$ in addition to non-radioactive dNTPs in the reaction mixture (see Materials and methods). For radioactive PCR, the linear range of amplification was determined beforehand and amplification ( $94^{\circ} \mathrm{C}$, $30 \mathrm{sec} ; 55^{\circ} \mathrm{C}, 30 \mathrm{sec} ; 72^{\circ} \mathrm{C}, 1 \mathrm{~min}$ ) was performed for 18 cycles for $36 B 4$ and 20 cycles for $18 S$ rRNA, 22 cycles for RARRES2, 25 cycles for $L T B P 2$ and 27 cycles for RARRES1, TYMS and HMGCR, respectively. (B and C) Signals from RT-PCR results were detected by Phosphoimager screens, quantified with TINA 2.0 program (Raytest, Straubenhardt, Germany), and normalized to the mRNA levels of the $36 B 4$ and $18 S$ rRNA genes.

Array-CGH. Array-CGH was carried out as described previously (18). In brief, endometriotic DNA and reference normal male DNA were labelled by random priming (BioPrime DNA labelling system, Invitrogen, Breda, The Netherlands) to incorporate Cy3-dCTP and Cy5-dCTP (Perkin-Elmer Life Sciences, Zaventem, Belgium), respectively. Non-incorporated nucleotides were removed using ProbeQuant G-50 Microcolumns (Amersham
Biosciences, Roosendaal, The Netherlands). Hybridization was carried out with labelled DNA mixed with Cot-1 DNA (Invitrogen) for 2 days to the in-house-developed Bacterial Artificial Chromosome array containing 5,659 clones spotted in triplicate, which provides an $\sim 1.0-\mathrm{Mb}$ resolution across the human genome. $\log 2$ ratios of $\mathrm{Cy} 3$ and $\mathrm{Cy} 5$ intensities for each spot were calculated. Data were processed as described (18) and plotted relative to the position of the clones. 
Table II. Down-regulated genes and ESTs in all 16 comparisons.

\begin{tabular}{|c|c|c|c|}
\hline Fold-down & GenBank ID & Gene description & Gene symbol \\
\hline 12.18 & NM_018123.1 & asp (abnormal spindle)-like, microcephaly associated (Drosophila) & ASPM \\
\hline 10.83 & AL561834 & Topoisomerase (DNA) II $\alpha 170 \mathrm{kDa}$ & TOP2A \\
\hline 10.60 & NM_014750.1 & Discs, large homolog 7 (Drosophila) & DLG7 \\
\hline 08.32 & AL524035 & Cell division cycle $2, \mathrm{G} 1$ to $\mathrm{S}$ and $\mathrm{G} 2$ to $\mathrm{M}$ & $\mathrm{CDC} 2$ \\
\hline 08.32 & NM_014736.1 & KIAA0101 gene product & KIAA0101 \\
\hline 07.21 & NM_018131.1 & Chromosome 10 open reading frame 3 & C10orf3 \\
\hline 06.06 & ВC001886.1 & Ribonucleotide reductase M2 polypeptide & RRM2 \\
\hline 05.28 & NM_001827.1 & CDC28 protein kinase regulatory subunit 2 & CKS2 \\
\hline 05.14 & NM_001071.1 & Thymidylate synthetase & TYMS \\
\hline 04.95 & AK027006.1 & Trinucleotide repeat containing 9 & TNRC9 \\
\hline 04.78 & AB032983.1 & KIAA1157 protein & KIAA1157 \\
\hline 04.78 & NM_014791.1 & Maternal embryonic leucine zipper kinase & MELK \\
\hline 04.54 & NM_001786.1 & Cell division cycle $2, \mathrm{G} 1$ to $\mathrm{S}$ and $\mathrm{G} 2$ to $\mathrm{M}$ & $\mathrm{CDC} 2$ \\
\hline 04.25 & BE407516 & Cyclin B1 & CCNB1 \\
\hline 04.12 & NM_024629.1 & Hypothetical protein FLJ23468 & FLJ23468 \\
\hline 03.29 & NM_016359.1 & Nucleolar protein ANKT & ANKT \\
\hline 03.11 & BF439316 & Transmembrane protein with EGF-like and two follistatin-like domains 1 & TMEFF1 \\
\hline 03.10 & AF213033.1 & Cyclin-dependent kinase inhibitor 3 (CDK2-associated dual specificity phosphatase) & CDKN3 \\
\hline 03.07 & AL518627 & 3-hydroxy-3-methylglutaryl-Coenzyme A reductase & HMGCR \\
\hline 03.03 & ВC000323.1 & Flap structure-specific endonuclease 1 & FEN1 \\
\hline 02.82 & NM_006486.1 & Fibulin 1 & FBLN1 \\
\hline 02.25 & AF037448.1 & NS1-associated protein 1 & NSAP1 \\
\hline
\end{tabular}

Smoothing with data was performed using the aCGHsmooth program (http://www.few.vu.nl/ vumarray/) to detect genomic aberrations.

Determination of telomerase activity (TRAP assay). In order to determine the enzymatic activity of telomerase in extracts from endometriotic and normal endometrium tissue samples, the Telomeric Repeat Amplification Protocol (TRAP) with the Trapeze Kit (Serologicals Corp., Norcross, GA, USA) was used, according to the manufacturer's instructions.

\section{Results}

Microarray data analysis. For data analysis, gene expression of the endometriotic lesion of each patient was compared to that of the eutopic endometrium of all 4 patients. In this way, the expression profiles of all 4 endometriotic lesions were compared to 4 different reference probes, leading to a total of 16 comparisons. Using this strategy, two groups of genes were identified. The first included 14 up-regulated (Table I), and the second included 22 down-regulated genes and ESTs in all 16 comparisons (Table II). Furthermore, 56 additional genes and ESTs were up-regulated in 15 out of 16 comparisons (Table III), and an additional 75 genes and ESTs were down-regulated in 15 out of 16 comparisons (Table IV).

Validation of microarray data. Expression of the following genes was used for initial in silico validation: $M A G E-A 1$ and 2, MAGE-B1-4, MAGE-C1, BAGE and GAGE1-4 and 6-7. These genes are expressed only in malignancies but not in normal tissues, with some rare exceptions (e.g. normal testis and placenta) (19). Consistent with their tumor-associated expression pattern, all of these genes exhibited an 'absent call' in all samples tested with high-density oligonucleotide microarrays.

Five genes were selected for microarray data validation with RT-PCR. Four of these genes, RARRES1, LTBP2, $T Y M S$, and $H M G C R$, showed significant variation in all 16 comparisons. There were two probe sets corresponding to RARRES1. The first (Affymetrix 221872_at) showed a 7.24fold-up, and the second (206392_s_at) a 5.66-fold-up variation. LTBP2 showed a 3.72-fold-up, TYMS a 5.14-fold-down, and $H M G C R$ a 3.07-fold-down variation. The fifth gene, RARRES2, was up-regulated in 14 out of 16 comparisons (21-fold-up). RARRES1 and 2 were selected as members of the same gene family, while $L T B P 2, T Y M S$, and HMGCR were randomly selected among genes showing significant variation.

Radioactive RT-PCR was used to detect and quantify expression of these genes (Fig. 1). For this purpose, total RNA was freshly isolated from the eutopic (normal) endometrium and corresponding ectopic tissue from 3 patients (no material was left for RNA isolation from patient 4 for these studies). The signals were quantified and normalized to the average signal values obtained from two different ubiquitously expressed genes, $36 B 4$ and $18 S \mathrm{rRNA}$, to minimize tissuespecific variation in the expression of the control genes (Fig. 1A). We found up-regulation of RARRES-1 (in average 15-fold), RARRES-2 (in average 9-fold) and LTBP-2 (in average 7-fold) (Fig. 1), and down-regulation of $H M G C R$ (in average 3.5-fold) and TYMS (in average 3-fold). Thus, RT-PCR 

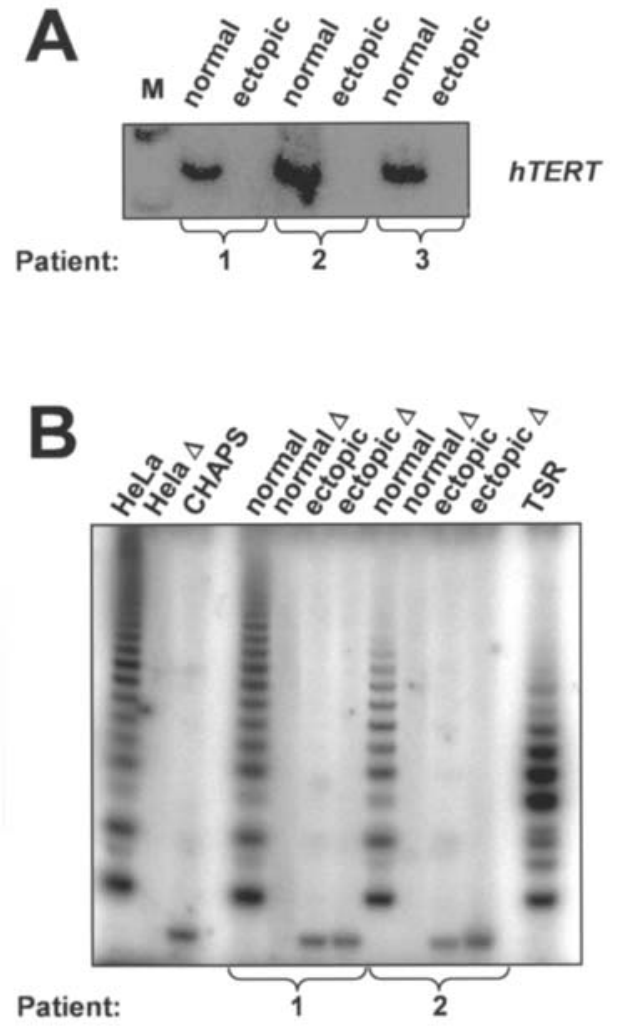

Figure 2. hTERT gene expression and telomerase activity are downregulated in ectopic endometrium. (A) RT-PCR was performed for the mRNA detection of the hTERT gene and (B) TRAP assay was performed to detect enzymatic activity of telomerase with tissue samples obtained from patients 1 and 2. RT-PCR and TRAP assays were performed as described in Materials and methods. For radioactive PCR, the same cDNA was used as in Fig. 1 and amplification $\left(94^{\circ} \mathrm{C}, 30 \mathrm{sec} ; 55^{\circ} \mathrm{C}, 30 \mathrm{sec} ; 72^{\circ} \mathrm{C}, 1 \mathrm{~min}\right)$ was performed for 28 cycles for $h T E R T$. The loading controls (18S rRNA and $36 B 4$ mRNA levels) are shown in Fig. 1. M, 100 base pair ladder. One microgram of the 100 base pair ladder was end-labelled according to standard procedures, and $\sim 1000 \mathrm{cps}$ was loaded per lane.

results confirmed the microarray data. Differences in signal intensities between RT-PCR and microarray results were probably due to the different numbers of patients analyzed with the two methods, and inherent methodological differences. The expression of these genes was also analyzed by RT-PCR in endometriotic lesions from 10 additional patients, and the results were in line with those described above, with negligible variations between patients (data not shown).

Lack of telomerase activity and hTERT gene expression in ectopic endometrium. Telomerase activity is repressed in most human somatic tissues during differentiation processes, but it is strongly up-regulated in the vast majority of tumors. Telomerase activity has been previously detected in normal endometrium (20), but it has not been examined in endometriosis. Regulation of telomerase activity occurs primarily at the level of transcriptional initiation of the hTERT (human telomerase reverse transcriptase) gene $(21,22)$. Thus, the presence or absence of TERT gene mRNA, and consequently telomerase activity, may be indicative of the proliferative capacity of a given cell, a prerequisite for malignancy. hTERT exhibited an 'absent call' on the microarray analysis in all 8 probes tested (4 ectopic and 4 eutopic endometrium probes). We reasoned that this might be due to very low levels of hTERT mRNA (23). For this reason, a very sensitive method, radioactive RT-PCR, was used to detect low levels of mRNA. hTERT mRNA was detectable in all normal endometrium samples, but completely absent in endometriosis samples (Fig. 2A). Moreover, telomerase activity was detectable in samples from normal endometrium but absent in endometriosis samples (Fig. 2B).

Array-CGH analysis of endometriotic lesions. Array-CGH was performed on selected endometriotic tissues (including the samples used in the gene expression analysis) in order to screen for genomic aberrations, which could possibly influence gene expression. Identification of such aberrations could also provide indications of the possible association between endometriosis and neoplastic disease, and endometriosis dissemination. Genomic information obtained with conventional CGH is limited to a resolution of $\sim 10 \mathrm{Mb}$, since the target DNA is highly condensed and supercoiled within the chromosome. Thus, array-based CGH was used in order to achieve a resolution approaching $1 \mathrm{MB}$. For automated identification of breakpoints and smoothing of array-CGH data the aCGHsmooth program was used as described previously (24). Reliability of array-CGH results was confirmed through hybridization of the female endometriotic DNA with male reference DNA. As expected, DNA gain was detected on chromosome $\mathrm{X}$ (numbered as chromosome 23), while DNA loss was detected on chromosome Y (chromosome 24). Representative examples are shown in Fig. 3A and B. No genomic aberrations were detected in any of the analyzed endometriotic lesions (Fig. 3).

\section{Discussion}

Large-scale gene expression analyses of endometriosis and normal endometrium have been previously reported (25-28), but only a subset of the human genome was analyzed in these studies with various methodological approaches. In the present study, gene expression profiles of advanced ovarian endometriotic lesions and corresponding normal endometrium were analyzed with high-density oligonucleotide microarrays, covering for the first time almost the entire human genome by screening for $>40,000$ human genes and ESTs. Notably, all biopsies in this study were taken in the proliferative phase, since gene expression profiles in the eutopic endometrium differ between the two phases of the menstrual cycle (29). Furthermore, the microarray method used allowed robust data analysis, since signal intensities of each sample could be compared to those of any other sample generated under the same experimental conditions, and thus more than one normal endometrium sample could be used as reference.

Moreover, normal and ectopic endometrium samples were taken from the same patients, allowing gene expression analysis with minimal genetic background heterogeneity. Genetic heterogeneity between individuals confounds the comparison of gene expression profiles between individual patients. CGH with parallel gene expression microarray analyses have shown that individual genetic alterations can directly lead to gene expression dysregulation (30). These 
A

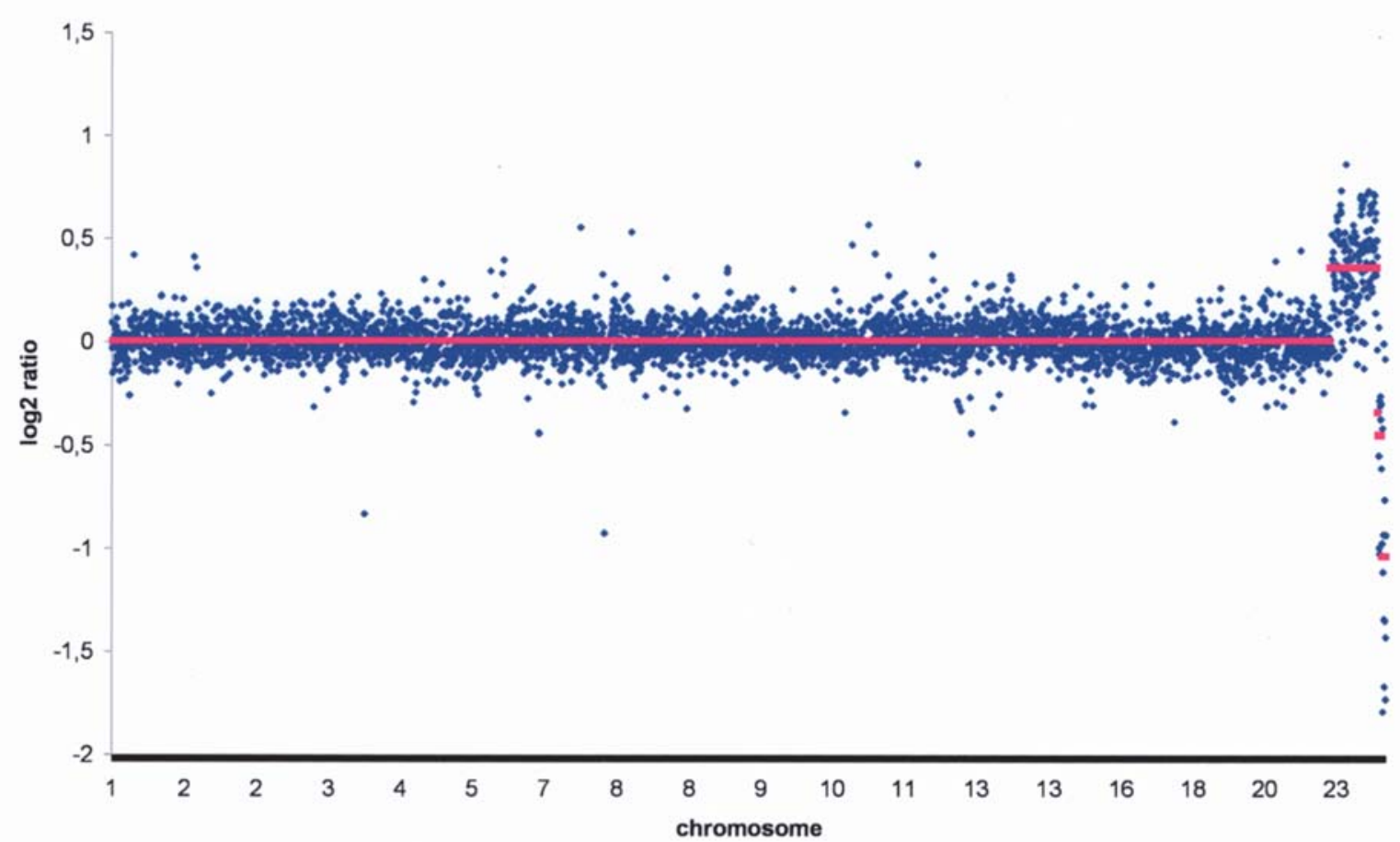

B

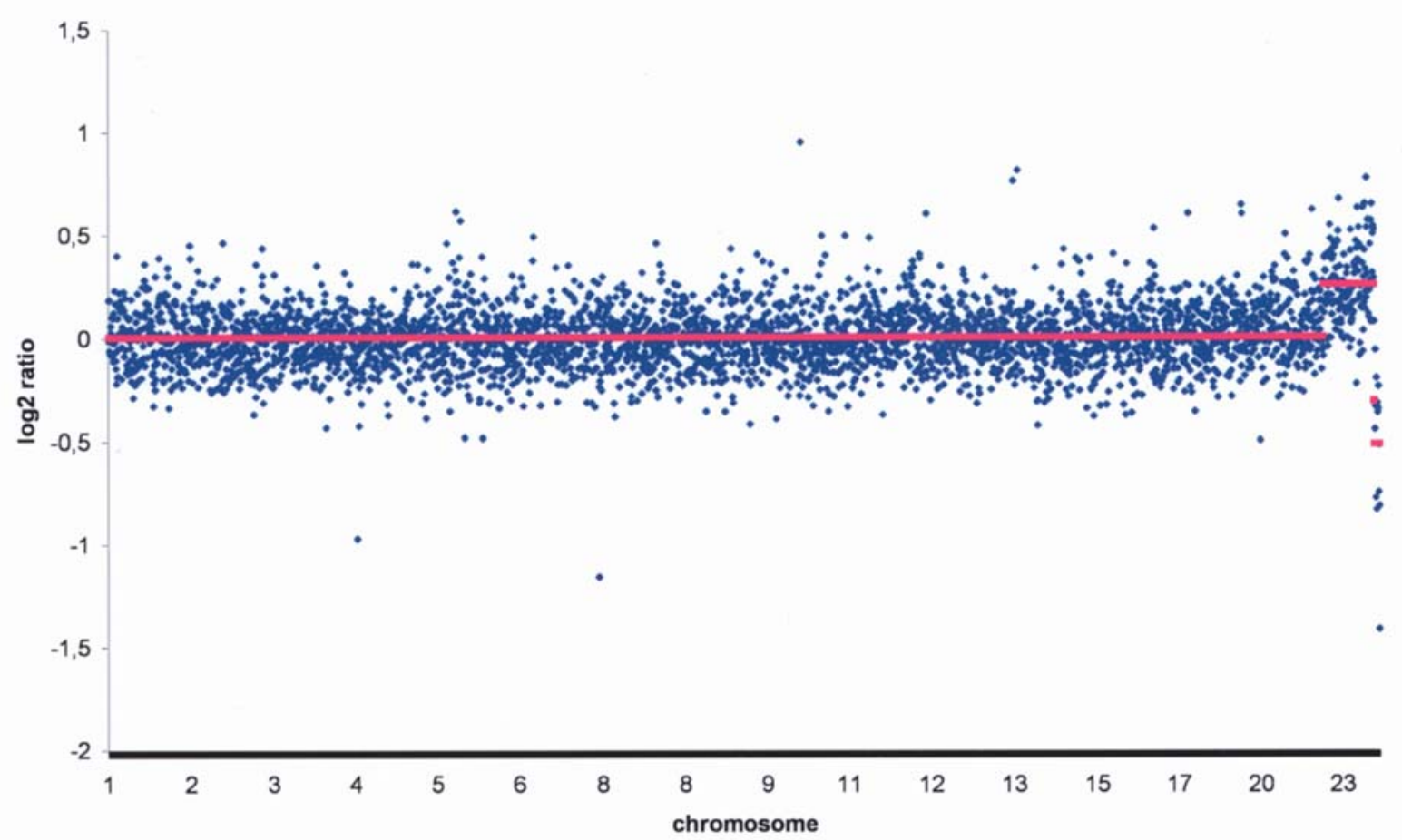

Figure 3. No genomic aberrations were detected in DNA of endometriotic lesions. Array-CGH from two patients (A and B) was carried out as described. The $\log 2$ ratios are plotted on individual chromosomes. Blue representing the $\log 2$ ratios of the hybridization values and violet representing the breakpoints after the smoothing with the aCGHsmooth program are used to facilitate the detection of genomic aberrations.

limitations can be eliminated only in rare cases in which the patient and the healthy control are genetically identical, as is the case with identical twins; this approach has been previously used in two microarray studies, involving identical twins discordant for type I diabetes (31) and multiple myeloma (32). In the present study, microarray data were analyzed with a minimal genetic background approach, comparing in essence four sets of 'identical twin' probes, as previously described $(31,32)$.
Though studies with conventional CGH with human metaphase chromosomes $(33,34)$, allowing a resolution of $10 \mathrm{MB}$, and high-resolution CGH (35) have previously described certain aberrations in endometriotic epithelial cells, our analysis by array-CGH to a much higher resolution of $1.0 \mathrm{Mb}$ did not show any specific genomic aberrations in endometriosis samples. This contradiction is probably due to different experimental settings, patient characteristics, and disease stages. Moreover, genome variations such as segmental 
Table III. Up-regulated genes and ESTs in 15 out of 16 comparisons.

\begin{tabular}{|c|c|c|c|}
\hline Fold-up & GenBank ID & Gene description & Gene symbol \\
\hline 30.25 & AA707199 & Neurotrophic tyrosine kinase, receptor, type 2 & NTRK2 \\
\hline 21.76 & NM_012134.1 & Leiomodin 1 (smooth muscle) & LMOD1 \\
\hline 19.53 & NM_022870.1 & Myosin, heavy polypeptide 11 , smooth muscle & MYH11 \\
\hline 12.72 & S67238.1 R[3]C & Myosin, heavy polypeptide 11 , smooth muscle & MYH11 \\
\hline 12.55 & NM_001442.1 & Fatty acid binding protein 4 , adipocyte & FABP4 \\
\hline 11.81 & AL359062.1 & Homo sapiens mRNA full length insert cDNA clone EUROIMAGE 1913076 & \\
\hline 08.32 & NM_000300.1 & Phospholipase A2, group IIA (platelets, synovial fluid) & PLA2G2A \\
\hline 06.96 & NM_005525.1 & Hydroxysteroid (11- $\beta)$ dehydrogenase 1 & HSD11B1 \\
\hline 06.50 & AI807950 & ESTs, weakly similar to hypothetical protein FLJ20489 [Homo sapiens] & \\
\hline 05.76 & NM_005965.1 & Myosin, light polypeptide kinase & MYLK \\
\hline 05.61 & BE551451 & ESTs & \\
\hline 05.12 & X57812.1 & Immunoglobulin $\lambda$ joining 3 & IGLJ3 \\
\hline 04.86 & M63438.1 & Immunoglobulin $\kappa$ constant & IGKC \\
\hline 04.52 & NM_003246.1 & Thrombospondin 1 & THBS1 \\
\hline 04.42 & M87789.1 & Immunoglobulin heavy constant $\gamma 3$ (G3m marker) & IGHG3 \\
\hline 04.34 & NM_002084.2 & Glutathione peroxidase 3 (plasma) & GPX3 \\
\hline 04.18 & AF288391.1 & Chromosome 1 open reading frame 24 & C1orf24 \\
\hline 04.16 & NM_000362.2 & Tissue inhibitor of metalloproteinase 3 (Sorsby fundus dystrophy, pseudoinflammatory) & TIMP3 \\
\hline 04.03 & AL577531 & Caldesmon 1 & CALD1 \\
\hline 03.97 & BC005332.1 & Immunoglobulin $\kappa$ constant & IGKC \\
\hline 03.93 & NM_013281.1 & Fibronectin leucine-rich transmembrane protein 3 & FLRT3 \\
\hline 03.91 & AW027333 & Hypothetical protein LOC253827 & LOC253827 \\
\hline 03.86 & NM_007203.1 & A kinase (PRKA) anchor protein 2 & AKAP2 \\
\hline 03.85 & AA706788 & Hs mRNA; cDNA DKFZp434C1915 (from clone DKFZp434C1915); partial cds & \\
\hline 03.81 & AA680302 & Immunoglobulin $\lambda$ joining 3 & IGLJ3 \\
\hline 03.78 & AW151360 & ESTs & \\
\hline 03.73 & M87790.1 & Immunoglobulin $\lambda$ joining 3 & IGLJ3 \\
\hline 03.70 & NM_001613.1 & Actin, $\alpha 2$, smooth muscle, aorta & ACTA2 \\
\hline 03.67 & AV726673 & Thrombospondin 1 & THBS1 \\
\hline 03.66 & NM_022083.1 & Chromosome 1 open reading frame 24 & C1orf24 \\
\hline 03.57 & NM_014840.1 & KIAA0537 gene product & ARK5 \\
\hline 03.57 & BG540494 & A kinase (PRKA) anchor protein 2 & AKAP2 \\
\hline 03.48 & BG485135 & Immunoglobulin $\kappa$ constant & IGKC \\
\hline 03.45 & NM_001299.1 & Calponin 1, basic, smooth muscle & CNN1 \\
\hline 03.41 & ВC002416.1 & Biglycan & BGN \\
\hline 03.36 & AA845258 & Biglycan & BGN \\
\hline 03.31 & NM_003289.1 & Tropomyosin $2(ß)$ & TPM2 \\
\hline 03.23 & AI658662 & Homo sapiens cDNA FLJ20767 fis, clone COL06986 & \\
\hline 03.17 & NM_005195.1 & CCAAT/enhancer binding protein $(\mathrm{C} / \mathrm{EBP}), \Delta$ & CEBPD \\
\hline 03.01 & NM_004342.2 & Caldesmon 1 & CALD1 \\
\hline 02.99 & AW978896 & Homo sapiens hAWMS1 mRNA, complete cds. & \\
\hline 02.87 & AI754423 & Colon carcinoma-related protein & LOC51159 \\
\hline 02.82 & AB046817.1 & Synaptotagmin-like 2 & SYTL2 \\
\hline 02.64 & AF132202.1 & PRO1073 protein & PRO1073 \\
\hline 02.61 & NM_000014.3 & $\alpha$-2-macroglobulin & $\mathrm{A} 2 \mathrm{M}$ \\
\hline 02.56 & AF164622.1 & Golgin-67 & GOLGIN-67 \\
\hline 02.52 & AL583520 & Caldesmon 1 & CALD1 \\
\hline 02.49 & NM_001912.1 & Cathepsin L & CTSL \\
\hline 02.39 & AW005982 & PRO1073 protein & PRO1073 \\
\hline 02.38 & AL136842.1 & CDC42 effector protein (Rho GTPase binding) 3 & CDC42EP3 \\
\hline 02.29 & BF221852 & LIM domain containing preferred translocation partner in lipoma & LPP \\
\hline 02.29 & AW513612 & Hypothetical protein LOC119587 & LOC119587 \\
\hline 02.21 & AI123567 & Formin homology 2 domain containing 2 & FHOD2 \\
\hline 02.14 & AA524053 & Splicing factor, arginine/serine-rich $7,35 \mathrm{kDa}$ & SFRS7 \\
\hline 02.06 & NM_014128.1 & & \\
\hline 02.06 & AB000889.1 & Phosphatidic acid phosphatase type $2 \mathrm{~B}$ & PPAP2B \\
\hline
\end{tabular}


Table IV. Down-regulated genes and ESTs in 15 out of 16 comparisons.

\begin{tabular}{|c|c|c|c|}
\hline Fold-down & GenBank ID & Gene description & Gene symbol \\
\hline 14.74 & NM_021127.1 & Phorbol-12-myristate-13-acetate-induced protein 1 & PMAIP1 \\
\hline 12.83 & NM_002160.1 & Tenascin C (hexabrachion) & TNC \\
\hline 12.07 & NM_006101.1 & Highly expressed in cancer, rich in leucine heptad repeats & HEC \\
\hline 08.88 & NM_004456.1 & Enhancer of zeste homolog 2 (Drosophila) & $\mathrm{EZH} 2$ \\
\hline 08.28 & NM_001168.1 & Baculoviral IAP repeat-containing 5 (survivin) & BIRC5 \\
\hline 06.70 & NM_001255.1 & CDC20 cell division cycle 20 homolog (S. cerevisiae) & CDC20 \\
\hline 06.28 & Y11339.2 & GalNAc $\alpha$-2, 6-sialyltransferase I, long form & ST6GalNAcI \\
\hline 06.17 & NM_003318.1 & TTK protein kinase & TTK \\
\hline 05.78 & BF589515 & Hypothetical protein FLJ34221 & FLJ34221 \\
\hline 05.63 & D88357.1 & Cell division cycle $2, \mathrm{G} 1$ to $\mathrm{S}$ and $\mathrm{G} 2$ to $\mathrm{M}$ & $\mathrm{CDC} 2$ \\
\hline 05.30 & NM_001211.2 & BUB1 budding uninhibited by benzimidazoles 1 homolog $\beta$ (yeast) & BUB1B \\
\hline 05.21 & NM_001996.1 & Fibulin 1 & FBLN1 \\
\hline 05.10 & AL574096 & Tissue factor pathway inhibitor 2 & TFPI2 \\
\hline 04.88 & NM_004701.2 & Cyclin B2 & $\mathrm{CCNB} 2$ \\
\hline 04.82 & AK025084.1 & Trinucleotide repeat containing 9 & TNRC9 \\
\hline 04.80 & BG054916 & Patched homolog (Drosophila) & PTCH \\
\hline 04.76 & NM_002358.2 & MAD2 mitotic arrest deficient-like 1 (yeast) & MAD2L1 \\
\hline 04.72 & NM_001809.2 & Centromere protein $\mathrm{A}, 17 \mathrm{kDa}$ & CENPA \\
\hline 04.72 & AK023208.1 & Anillin, actin binding protein (scraps homolog, Drosophila) & ANLN \\
\hline 04.38 & AL547946 & Progesterone receptor membrane component 1 & PGRMC1 \\
\hline 04.21 & NM_003981.1 & Protein regulator of cytokinesis 1 & PRC1 \\
\hline 04.02 & AI419030 & Glycoprotein M6B & GPM6B \\
\hline 03.98 & $\mathrm{AI} 346350$ & Polymyositis/scleroderma autoantigen 1, $75 \mathrm{kDa}$ & PMSCL1 \\
\hline 03.78 & NM_012259.1 & Hairy/enhancer-of-split related with YRPW motif 2 & HEY2 \\
\hline 03.78 & ВC005978.1 & Karyopherin $\alpha 2$ (RAG cohort 1 , importin $\alpha 1)$ & KPNA2 \\
\hline 03.78 & NM_004702.1.1 & Cyclin E2 & CCNE2 \\
\hline 03.62 & NM_004900.1 & Apolipoprotein B mRNA editing enzyme, catalytic polypeptide-like 3B & АРОВЕС3В \\
\hline 03.59 & U36189.1 & Chromosome 5 open reading frame 13 & C5orf13 \\
\hline 03.53 & NM_003524.1 & Histone $1, \mathrm{H} 2 \mathrm{bh}$ & HIST1H2BH \\
\hline 03.42 & D13889.1 & Inhibitor of DNA binding 1, dominant negative helix-loop-helix protein & ID1 \\
\hline 03.15 & NM_021968.1 & & \\
\hline 03.11 & AI431730 & $\begin{array}{l}\text { A disintegrin-like and metalloprotease (reprolysin type)with } \\
\text { thrombospondin type } 1 \text { motif, } 9\end{array}$ & ADAMTS9 \\
\hline 03.07 & NM_004415.1 & Desmoplakin (DPI, DPII) & DSP \\
\hline 02.99 & NM_003878.1 & $\gamma$-glutamyl hydrolase (conjugase, folylpolygammaglutamyl hydrolase) & GGH \\
\hline 02.90 & AK026161.1 & $\mathrm{Ca}^{2+}$-dependent endoplasmic reticulum nucleoside diphosphatase & SHAPY \\
\hline 02.88 & NM_002266.1 & Karyopherin $\alpha 2$ (RAG cohort 1 , importin $\alpha 1)$ & KPNA2 \\
\hline 02.87 & NM_004219.2 & Pituitary tumor-transforming 1 & PTTG1 \\
\hline 02.85 & NM_002105.1 & $\mathrm{H} 2 \mathrm{~A}$ histone family, member $\mathrm{X}$ & $\mathrm{H} 2 \mathrm{AFX}$ \\
\hline 02.84 & AL563283 & Androgen-induced basic leucine zipper & AIBZIP \\
\hline 02.83 & NM_012177.1 & F-box only protein 5 & FBXO5 \\
\hline 02.72 & AU153848 & Rac GTPase activating protein 1 & RACGAP1 \\
\hline 02.72 & NM_002402.1 & Mesoderm-specific transcript homolog (mouse) & MEST \\
\hline 02.72 & NM_004772.1 & Chromosome 5 open reading frame 13 & C5orf13 \\
\hline 02.69 & M69148.1 & Midkine (neurite growth-promoting factor 2) & MDK \\
\hline 02.69 & NM_015677.1 & Likely ortholog of mouse Sh3 domain YSC-like 1 & SH3YL1 \\
\hline 02.56 & NM_006452.1 & $\begin{array}{l}\text { Phosphoribosylaminoimidazole carboxylase, phosphoribosylaminoimidazole } \\
\text { succinocarboxamide synthetase }\end{array}$ & PAICS \\
\hline 02.52 & NM_006451.1 & Olyadenylate binding protein-interacting protein 1 & PAIP1 \\
\hline 02.48 & D87292.1 & Thiosulfate sulfurtransferase (rhodanese) & TST \\
\hline 02.47 & NM_002592.1 & Proliferating cell nuclear antigen & PCNA \\
\hline 02.45 & NM_006667.2 & Progesterone receptor membrane component 1 & PGRMC1 \\
\hline 02.44 & AB000888.1 & Phosphatidic acid phosphatase type $2 \mathrm{~A}$ & PPAP2A \\
\hline 02.43 & AA534817 & Endothelial differentiation, sphingolipid G-protein-coupled receptor, 3 & EDG3 \\
\hline
\end{tabular}


Table IV. Continued.

\begin{tabular}{|c|c|c|c|}
\hline Fold-down & GenBank ID & Gene description & Gene symbol \\
\hline 02.41 & NM_018204.1 & Cytoskeleton associated protein 2 & CKAP2 \\
\hline 02.40 & NM_020987.1 & Ankyrin 3, node of Ranvier (ankyrin G) & ANK3 \\
\hline 02.34 & AF014403.1 & Phosphatidic acid phosphatase type $2 \mathrm{~A}$ & PPAP2A \\
\hline 02.34 & Z95331 & Fibulin 1 & FBLN1 \\
\hline 02.31 & M96789 & Gap junction protein, $\alpha 4,37 \mathrm{kDa}$ (connexin 37 ) & GJA4 \\
\hline 02.31 & AI970157 & Glycine cleavage system protein $\mathrm{H}$ (aminomethyl carrier) & GCSH \\
\hline 02.31 & NM_006334.1 & Olfactomedin 1 & OLFM1 \\
\hline 02.29 & NM_006117.1 & Peroxisomal D3,D2-enoyl-CoA isomerase & PECI \\
\hline 02.29 & NM_005496.1 & SMC4 structural maintenance of chromosomes 4-like 1 (yeast) & SMC4L1 \\
\hline 02.25 & NM_002915.1 & Replication factor C (activator 1) $3,38 \mathrm{kDa}$ & RFC3 \\
\hline 02.19 & NM_001070.1 & Tubulin, $\gamma 1$ & TUBG1 \\
\hline 02.18 & NM_001123.1 & Adenosine kinase & ADK \\
\hline 02.18 & AA112507 & LSM4 homolog, U6 small nuclear RNA associated (S. cerevisiae) & LSM4 \\
\hline 02.13 & L04636.1 & Complement component 1, q subcomponent binding protein & C1QBP \\
\hline 02.13 & NM_005815.1 & Kruppel-type zinc finger $(\mathrm{C} 2 \mathrm{H} 2)$ & ZK1 \\
\hline 02.11 & AA902652 & $\begin{array}{l}\text { Phosphoribosylaminoimidazole carboxylase, phosphoribosylaminoimidazole } \\
\text { succinocarboxamide synthetase }\end{array}$ & PAICS \\
\hline 02.10 & S81916.1 & $\begin{array}{l}\text { Phosphoglycerate kinase \{alternatively spliced\} [human, phosphoglycerate } \\
\text { kinase deficient patient with episodes of muscl, mRNA partial mutant, } 307 \mathrm{nt} \text { ] }\end{array}$ & \\
\hline 02.08 & AW235061 & $\begin{array}{l}\text { Solute carrier family } 1 \text { (neuronal/epithelial high affinity } \\
\text { glutamate transporter, system Xag), member } 1\end{array}$ & SLC1A1 \\
\hline 02.07 & NM_004999.1 & Myosin VI & MYO6 \\
\hline 02.05 & AW237404 & Glycine cleavage system protein $\mathrm{H}$ (aminomethyl carrier) & GCSH \\
\hline 02.04 & NM_002482.1 & Nuclear autoantigenic sperm protein (histone-binding) & NASP \\
\hline 02.03 & NM_001954.2 & Discoidin domain receptor family, member 1 & DDR1 \\
\hline 02.03 & ВС004439.1 & Translocase of inner mitochondrial membrane 17 homolog A (yeast) & TIMM17A \\
\hline
\end{tabular}

duplications might have been discovered by the conventional CGH methods depending on the reference DNA used. We excluded measurement of genome variations by using male reference DNA of a mixed pool of different individuals. Importantly, in the endometriosis samples analyzed with gene expression microarrays no genomic alterations were found by array-CGH. These findings confirm that genetic background heterogeneity in our gene expression analysis was indeed minimal, and were in line with our gene expression data demonstrating the minimal malignant potential of endometriosis.

Up-regulated candidate genes identified with gene expression microarray analysis in the present study included genes encoding proteins involved in immunologic processes (LTBP2, IGJ, IGKC, IGLJ3, MSR1, FCGR2B, IGHG3, IGL@ , IGLV, Ig $\kappa$ light chain mRNA, CCL18, TNFSF13B, CXCL12, $C R L F 3)$, and genes involved in cancer (TAGLN, GLTSCR2, WISP2I), including putative tumor-suppressor genes (RARRES1 and 2, ARHI and CREBL2) (Tables I and III). Down-regulated candidate genes included genes involved in cell metabolism and homeostasis (RRM2, H2AFX, CENPA, $H M G C R, A P O B E C 3 B)$, genes involved in the cell cycle (cyclins B1,B2 and E2,CDKN3,CKS2,CDC2, TOP2A, $M A D 2 L 1$ ), and $P T T G 1$, a gene with transforming activity in vitro and tumorigenic activity in vivo (Tables II and IV). These genes have not been identified by previous microarray analyses of endometriosis, apparently due to different method- ological approaches, lower number of genes analyzed in previous studies, and different subsets of patients, as discussed above.

Altogether, our results showing up-regulation of putative tumor-suppressor genes such as RARRES1 and RARRES2 and down-regulation of genes involved in the cell cycle suggest that advanced ovarian endometriosis is a highly differentiated tissue with minimal proliferative capacity. Moreover, these conclusions are further supported by the absence of both hTERT gene expression and telomerase activity with a distinct methodological approach. This state of high tissue differentiation does not allow definitive conclusions to be made with respect to the etiopathogenesis of endometriosis, but overall, these data suggest that advanced ovarian endometriosis is unlikely to be a precursor lesion of cancer. The lack of detectable genomic aberrations in endometriosis with highresolution array-CGH analysis is in line with these findings. Modulated genes identified in this setting should be further evaluated individually in order to define their role in endometriosis.

\section{Acknowledgements}

The authors gratefully thank Prof. Dr. W. Deppert for his support as well as critical discussions and comments on this project. We also thank K. Reeck for the excellent technical assistance. This study was supported by the Deutsche 
Krebshilfe (Dr. Mildred Scheel Stiftung) grant 10-2086-Gü 1; and an 'Annual grant for scientific research in the field of Gynecology' in the name of George Papanicolaou awarded by Procter \& Gamble Company (Greek Branch).

\section{References}

1. Cassina PC, Hauser M, Kacl G, Imthurn B, Schroder S and Weder W: Catamenial hemoptysis. Diagnosis with MRI. Chest 111: 1447-1450, 1997.

2. Dragoumis K, Mikos T, Zafrakas M, Assimakopoulos E, Stamatopoulos $\mathrm{P}$ and Bontis J: Endometriotic uterocutaneous fistula after cesarean section - A case report. Gynecol Obstet Invest 57: 90-92, 2004

3. Vinatier D, Orazi G, Cosson M and Dufour P: Theories of endometriosis. Eur J Obstet Gynecol Reprod Biol 96: 21-34, 2000.

4. Ueki M: Histologic study of endometriosis and examination of lymphatic drainage in and from the uterus. Am J Obstet Gynecol 165: 201-209, 1991.

5. Donnez J, Van Langendonckt A, Casanas-Roux F, Van Gossum JP, Pirard C, Jadoul P, Squifflet J and Smets M: Current thinking on the pathogenesis of endometriosis. Gynecol Obstet Invest 54 (suppl 1): 52-62, 2002.

6. Starzinski-Powitz A, Handrow-Metzmacher $\mathrm{H}$ and Kotzian S: The putative role of cell adhesion molecules in endometriosis: can we learn from tumour metastasis? Mol Med Today 5: 304-309, 1999

7. Obata K and Hoshiai H: Common genetic changes between endometriosis and ovarian cancer. Gynecol Obstet Invest 50 (suppl 1): 39-43, 2000.

8. Thomas EJ and Campbell IG: Molecular genetic defects in endometriosis. Gynecol Obstet Invest 50 (suppl 1): 44-50, 2000.

9. Oral E, Ilvan S, Tustas E, Korbeyli B, Bese T, Demirkiran F, Arvas $M$ and Kosebay D: Prevalence of endometriosis in malignant epithelial ovary tumours. Eur J Obstet Gynecol Reprod Biol 109: 97-101, 2003.

10. Modesitt SC, Tortolero-Luna G, Robinson JB, Gershenson DM and Wolf JK: Ovarian and extraovarian endometriosisassociated cancer. Obstet Gynecol 100: 788-795, 2002.

11. Somigliana E, Viganó P, Parazzini F, Stoppelli S, Giambattista E and Vercellini P: Association between endometriosis and cancer: a comprehensive review and a critical analysis of clinical and epidemiological evidence. Gynecol Oncol 101: 331341, 2006.

12. Vercellini P, Scarfone G, Bolis G, Stellato G, Carinelli S and Crosignani PG: Site of origin of epithelial ovarian cancer: the endometriosis connection. BJOG 107: 1155-1157, 2000.

13. Borgfeldt $\mathrm{C}$ and Andolf E: Cancer risk after hospital discharge diagnosis of benign ovarian cysts and endometriosis. Acta Obstet Gynecol Scand 83: 395-400, 2004.

14. Brinton LA, Gridley G, Persson I, Baron J and Bergqvist A: Cancer risk after a hospital discharge diagnosis of endometriosis. Am J Obstet Gynecol 176: 572-579, 1997.

15. Rajagopalan D: A comparison of statistical methods for analysis of high density oligonucleotide array data. Bioinformatics 19: 1469-1476, 2003.

16. Bonner AE, Lemon WJ and You M: Gene expression signatures identify novel regulatory pathways during murine lung development: implications for lung tumorigenesis. J Med Genet 40: 408-417, 2003

17. Doniger SW, Salomonis N, Dahlquist KD, Vranizan K, Lawlor SC and Conklin BR: MAPPFinder: using gene ontology and GenMAPP to create a global gene-expression profile from microarray data. Genome Biol 4: R7, 2003.

18. Smeets SJ, Braakhuis BJM, Abbas S, Snijders PJF, Ylstra B, van de Wiel MA, Meijer GA, Leemans CR and Brakenhoff RH: Genome-wide DNA copy number alterations in head and neck squamous cell carcinomas with or without oncogene-expressing human papillomavirus. Oncogene 25: 2558-2564, 2006.

19. Otte M, Zafrakas M, Riethdorf L, Pichlmeyer U, Löning T, Jänicke F and Pantel K: MAGE-A gene expression profile in primary breast cancer. Cancer Res 61: 6682-6687, 2001.
20. Ulaner GA, Hu JF, Vu TH, Oruganti H, Giudice LC and Hoffman AR: Regulation of telomerase by alternate splicing of human telomerase reverse transcriptase (hTERT) in normal and neoplastic ovary, endometrium and myometrium. Int $\mathrm{J}$ Cancer 85: 330-335, 2000.

21. Meyerson M, Counter CM, Eaton EN, Ellisen LW, Steiner P, Caddle SD, Ziaugra L, Beijersbergen RL, Davidoff MJ, Liu Q, Bacchetti S, Haber DA and Weinberg RA: hEST2, the putative human telomerase catalytic subunit gene, is up-regulated in tumor cells and during immortalization. Cell 90: 785-795, 1997.

22. Günes C, Lichtsteiner S, Vasserot AP and Englert C: Expression of the hTERT gene is regulated at the level of transcriptional initiation and repressed by Mad1. Cancer Res 60: 2116-2121, 2000.

23. Ducrest AL, Amacker M, Mathieu YD, Cuthbert AP, Trott DA, Newbold RF, Nabholz M and Lingner J: Regulation of human telomerase activity: repression by normal chromosome 3 abolishes nuclear telomerase reverse transcriptase transcripts but does not affect c-Myc activity. Cancer Res 61: 7594-7602, 2001.

24. Jong K, Marchiori E, Meijer G, Vaart AV and Ylstra B: Breakpoint identification and smoothing of array comparative genomic hybridization data. Bioinformatics 20: 3636-3637, 2004.

25. Lebovic DI, Mueller MD and Taylor RN: Immunobiology of endometriosis. Fertil Steril 75: 1-10, 2001.

26. Eyster KM, Boles AL, Brannian JD and Hansen KA: DNA microarray analysis of gene expression markers of endometriosis. Fertil Steril 77: 38-42, 2002.

27. Arimoto T, Katagiri T, Oda K, Tsunoda T, Yasugi T, Osuga Y, Yoshikawa H, Nishii O, Yano T, Taketani Y and Nakamura Y: Genome-wide cDNA microarray analysis of gene-expression profiles involved in ovarian endometriosis. Int J Oncol 22: 551-560, 2003.

28. Matsuzaki S, Canis M, Vaurs-Barriere C, Pouly JL, Boespflug-Tanguy O, Penault-Llorca F, Dechelotte P, Dastugue B, Okamura K and Mage G: DNA microarray analysis of gene expression profiles in deep endometriosis using laser capture microdissection. Mol Hum Reprod 10: 719-728, 2004.

29. Borthwick JM, Charnock-Jones DS, Tom BD, Hull ML, Teirney R, Phillips SC and Smith SK: Determination of the transcript profile of human endometrium. Mol Hum Reprod 9: 19-33, 2003.

30. Pollack JR, Sorlie T, Perou CM, Rees CA, Jeffrey SS, Lonning PE, Tibshirani R, Botstein D, Borresen-Dale A-L and Brown PO: Microarray analysis reveals a major direct role of DNA copy number alteration in the transcriptional program of human breast tumors. Proc Natl Acad Sci USA 99: 12963-12968, 2002 .

31. Wilson SB, Kent SC, Horton HF, Hill AA, Bollyky PL, Hafler DA, Strominger JL and Byrne MC: Multiple differences in gene expression in regulatory $\mathrm{V} \alpha 24 \mathrm{~J}_{\alpha} \mathrm{Q} \mathrm{T}$ cells from identical twins discordant for type I diabetes. Proc Natl Acad Sci USA 97: 7411-7416, 2000.

32. Munshi NC, Hideshima T, Carassco D, Shammas M, Auclair D, Davies F, Mitsiades N, Mitsiades C, Kim RS, Li C, Rajkumar SV, Fonseca R, Bergsagel L, Chauhan D and Anderson KC: Identification of genes modulated in multiple myeloma using genetically identical twin samples. Blood 103: 1799-1806, 2004.

33. Gogusev J, Bouquet de Joliniere J, Telvi L, Doussau M, du Manoir S, Stojkoski A and Levardon M: Genetic abnormalities detected by comparative genomic hybridization in a human endometriosisderived cell line. Mol Hum Reprod 6: 821-827, 2000.

34. Gogusev J, Bouquet de Joliniere J, Telvi L, Doussau M, du Manoir S, Stojkoski A and Levardon M: Detection of DNA copy number changes in human endometriosis by comparative genomic hybridization. Hum Genet 105: 444-451, 1999.

35. Wu Y, Strawn E, Basir Z, Wang Y, Halverson G, Jailwala P and Guo SW: Genomic alterations in ectopic and eutopic endometria of women with endometriosis. Gynecol Obstet Invest 62: 148-159, 2006. 